\title{
Sleep education in pediatric residency programs: a cross-cultural look
}

\author{
Jodi A Mindell ${ }^{1 *}$, Alex Bartle ${ }^{2}$, Youngmin Ahn ${ }^{3}$, Mahesh Babu Ramamurthy ${ }^{4}$, Huynh Thi Duy Huong ${ }^{5}$, \\ Jun Kohyama ${ }^{6}$, Albert M Li ${ }^{7}$, Nichara Ruangdaraganon ${ }^{8}$, Rini Sekartini ${ }^{9}$, Arthur Teng ${ }^{10}$ and Daniel YT Goh ${ }^{11}$
}

\begin{abstract}
Background: The objective of this study was to assess the prevalence of education about sleep and sleep disorders in pediatric residency programs and to identify barriers to providing such education.

Methods: Surveys were completed by directors of 152 pediatric residency programs across 10 countries (Hong Kong, India, Indonesia, Japan, Singapore, South Korea, Thailand, United States-Canada, and Vietnam).

Results: Overall, the average amount of time spent on sleep education is 4.4 hours (median $=2.0$ hours), with 23\% responding that their pediatric residency program provides no sleep education. Almost all programs (94.8\%) offer less than 10 hours of instruction. The predominant topics covered include sleep-related development, as well as normal sleep, sleep-related breathing disorders, parasomnias, and behavioral insomnia of childhood.

Conclusions: These results indicate that there is still a need for more efforts to include sleep-related education in all pediatric residency programs, as well as coverage of the breadth of sleep-related topics. Such education would be consistent with the increased recognition of the importance of sleep and under-diagnosis of sleep disorders in children and adolescents.
\end{abstract}

Keywords: Sleep, Sleep disorders, Residency, Education, Pediatrics

\section{Background}

Sleep disorders are highly prevalent in children and adolescents. Unfortunately they are often unrecognized and underdiagnosed [1], which can significantly impact mortality, morbidity, and quality of life [2]. For example, a recent study of the prevalence of diagnosed sleep disorders in pediatric primary care practices found that only $3.7 \%$ of children and adolescents were diagnosed with an ICD-9 sleep disorder, which is significantly lower than prevalence rates in epidemiological studies. One contributing factor for this low rate of recognition is the low awareness stemming from the limited education about sleep and sleep disorders in pediatric education [3]. Core competencies for sleep education were identified back in 2003, but there seems to be continued limited education in this area [4].

The three studies to date that have investigated the inclusion of education about sleep and sleep medicine in

\footnotetext{
* Correspondence: jmindell@sju.edu

'The Children's Hospital of Philadelphia and Saint Joseph's University, Philadelphia, USA

Full list of author information is available at the end of the article
}

medical schools were conducted in 1979, 1990, and most recently in 2011 [5-7]. These studies have found that typically less than 2 hours of sleep education are provided during medical school, with minimal change across the last 30 years. The only study of sleep education for pediatricians found an average of 4 hours of didactic lectures specific to pediatric sleep [8]. Furthermore, surveys of practicing pediatricians find greatly limited sleep knowledge, thus further emphasizing the need for education on sleep and sleep disorders both during medical school and during pediatric residency. One study of pediatricians found limited total knowledge about sleep, with approximately half of respondents reporting that they did not feel confident screening for sleep problems and the majority not feeling confident in their ability to evaluate $(66 \%)$ or treat $(75 \%)$ sleep problems in children [9]. A recent study of 346 pediatricians found that $96 \%$ believed it was their job to counsel patients/caregivers regarding sleep hygiene, however very few (18\%) reported ever receiving formal training on sleep disorders [10]. Clearly there is a great need for advancement of sleep education in pediatrics.

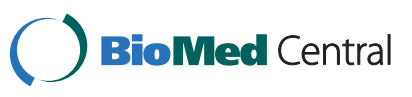

(c) 2013 Mindell et al.; licensee BioMed Central Ltd. This is an Open Access article distributed under the terms of the Creative Commons Attribution License (http://creativecommons.org/licenses/by/2.0), which permits unrestricted use, distribution, and reproduction in any medium, provided the original work is properly cited. 
To this end, the objective of this study was to investigate the inclusion of sleep education in pediatric residency programs. Pediatric residency programs were surveyed by members of the Asia-Pacific Pediatric Sleep Alliance (APPSA), a group of pediatric and sleep medicine specialists whose mission is to improve the understanding and management of sleep and sleep-related disorders in children across the Asia-Pacific region. The primary aims were to (1) assess the prevalence of didactic and non-didactic sleep education about sleep and sleep disorders in pediatric residency and (2) identify barriers to providing such education.

\section{Method}

A brief survey was sent to the directors of pediatric residency programs in 10 countries in the Asia-Pacific region (see Additional file 1), including Hong Kong (HK; $\mathrm{n}=11$ ), India (IN; $\mathrm{n}=38$ ), Indonesia (ID; $\mathrm{n}=10$ ), Japan (JP; $\mathrm{n}=$ 525), Singapore (SG; $n=2)$, South Korea $(n=57)$, Thailand $(\mathrm{TH} ; \mathrm{n}=15)$, and Vietnam (VN; $\mathrm{n}=7$ ). We also surveyed pediatric residency programs in the United States and Canada (US-CA; $\mathrm{n}=197$ ) as a comparison.

The survey was based on questionnaires used in previous studies $[6,8]$ with the majority of the survey identical to one that was completed in a previous study of medical schools [7] to enable comparisons across educational modalities. The first section asked about the amount of time allocated to sleep education in 6 domains (cardiology, ENT/ otololaryngology, neurology, respiratory/pulmonology, development, and psychiatry/psychology). The second section asked what sleep topics were covered in 7 areas (circadian rhythm disorders, hypersomnia, insomnia, pediatric sleep disorders, parasomnias, sleep apnea, and sleep related movement disorders) for adults and in pediatrics. Questions were asked about non-didactic sleep-related education opportunities, including non-elective and elective rotations, grand round speakers, guest lectures, case consults, and journal clubs. Finally, the respondents were asked to identify if any of the following barriers occurred if sleep was not included in their curriculum (insufficient time, lack of trained staff/ qualified instructors, lack of resources, lower priority, or not relevant to the program). In total, the survey included 24 questions and took approximately $3-5$ minutes to complete.

This study was approved by the Institutional Review Board at Saint Joseph's University. All surveys were completed online anonymously and all residency directors were contacted 2 or 3 times.

\section{Statistical analyses}

Descriptive data, including mean, median, and frequencies, are presented for all variables. Analyses of variance were used to compare across countries for all continuous variables. Chi-square analyses were conducted for categorical variables.

\section{Results}

\section{Response rate}

Similar to the previous study of medical schools, one of the most striking findings was the lack of response. Overall, only $17.6 \%$ (34.4\% excluding Japan) of the residency programs contacted $(n=152$ of 865$)$ responded. By country, response rates ranged from $7 \%$ to $100 \%$; specifically Hong Kong (27.3\%; $n=3$ of 11$)$, India (44.7\%; $\mathrm{n}=17$ of 38$)$, Indonesia $(90 \% ; \mathrm{n}=9$ of 10$)$, Japan $(6.7 \%$; $\mathrm{n}=35$ of 525$)$, Singapore ( $100 \% ; \mathrm{n}=2$ of 2$)$, South Korea (35.1\%; $\mathrm{n}=20$ of 57$)$, Thailand $(6.7 \% ; \mathrm{n}=1$ of 15$)$, United States-Canada (32.5\%; $\mathrm{n}=64$ of 197), and Vietnam $(10.0 \% ; n=1$ of 10$)$.

\section{Prevalence of sleep education}

All results reported are based on completed surveys. As seen in Table 1, across all pediatric residency programs, the sleep-related area that the highest percentage of schools reported covering was development (61\%), followed by respiratory (53\%) and neurology (45\%). Approximately one-quarter of all programs covered sleeprelated cardiology (26\%), ENT/otolaryngology (26\%), and psychiatry/psychology (24\%). Overall, the total time spent on sleep education across all sleep related domains ranged from a low of 50 minutes (Singapore) to a high of 788 minutes (India), with an average of 266 minutes across all programs, and significant differences across countries, $p<.05$. The median for each country ranged from 50 to 4200 minutes, with an average of $120 \mathrm{mi}$ nutes. Overall, $23.3 \%$ of programs reported providing no sleep-related education and $94.8 \%$ of programs offer less than 10 hours of instruction. A small minority of programs $(n=6 ; 5.2 \%)$ offered over 10 hours of instruction and two of those programs (1.4\%) report over 30 hours of education.

Regarding sleep disorders, about $75 \%$ of programs covered normal sleep, parasomnias, behavioral insomnia of childhood, and sleep-related rhythmic movements. Delayed sleep phase disorder (38\%) and sleep issues in medical disorders (33\%) were covered the least. In some countries, such as Hong Kong, Singapore, and the United States, most programs covered most sleep domains. In other countries, such as Thailand and Vietnam, few domains were covered. Again, there were significant differences across countries for all disorders, $\mathrm{p}<.05$.

\section{Non-didactic education}

In addition to didactic education, non-didactic education was provided across a number of domains. The most common educational opportunities included journal club (53\%), guest lectures (51\%), grand round speakers (47\%), and case consults (45\%). Elective rotations were also common (40\%), however non-elective rotations were less frequently provided (20\%). 
Table 1 Sleep education

\begin{tabular}{|c|c|c|c|c|c|c|c|c|c|c|}
\hline Country & $\begin{array}{c}H K \\
n=3\end{array}$ & $\begin{array}{c}\text { IN } \\
n=17\end{array}$ & $\begin{array}{c}\text { ID } \\
n=9\end{array}$ & $\begin{array}{c}\mathrm{JP} \\
\mathrm{n}=35\end{array}$ & $\begin{array}{c}\mathrm{KR} \\
\mathrm{n}=\mathbf{2 0}\end{array}$ & $\begin{array}{c}\text { SG } \\
n=2\end{array}$ & $\begin{array}{c}\text { TH } \\
n=1\end{array}$ & $\begin{array}{c}\mathrm{VN} \\
\mathrm{n}=1\end{array}$ & $\begin{array}{l}\text { US-CA } \\
n=64\end{array}$ & $\begin{array}{c}\text { Total } \\
\mathrm{n}=152\end{array}$ \\
\hline Specialty area (\% of respondents reporting covering each topic) & $\%$ & $\%$ & $\%$ & $\%$ & $\%$ & $\%$ & $\%$ & $\%$ & $\%$ & $\%$ \\
\hline Cardiology & 33 & 47 & 0 & 17 & 10 & 50 & 0 & 0 & 19 & 26 \\
\hline ENT/Otolaryngology & 0 & 29 & 0 & 20 & 30 & 100 & 0 & 0 & 31 & 26 \\
\hline Neurology & 33 & 53 & 0 & 54 & 60 & 100 & 0 & 0 & 39 & 45 \\
\hline Respiratory & 100 & 71 & 11 & 43 & 60 & 100 & 100 & 100 & 55 & 53 \\
\hline Development & 33 & 77 & 89 & 60 & 60 & 100 & 0 & 0 & 55 & 61 \\
\hline Psychiatry/Psychology & 33 & 41 & 0 & 23 & 45 & 50 & 0 & 0 & 17 & 24 \\
\hline Total (mean minutes) & 420 & 788 & 77 & 420 & 281 & 50 & 180 & 120 & 162 & 266 \\
\hline Total (median minutes) & 420 & 240 & 90 & 60 & 210 & 50 & 180 & 120 & 120 & 120 \\
\hline Specialty topics (\% of respondents reporting covering each topic) & $\%$ & $\%$ & $\%$ & $\%$ & $\%$ & $\%$ & $\%$ & $\%$ & $\%$ & $\%$ \\
\hline Normal sleep & 100 & 65 & 89 & 37 & 80 & 100 & 0 & 100 & 95 & 76 \\
\hline Delayed sleep phase disorder & 67 & 12 & 44 & 17 & 30 & 50 & 0 & 0 & 58 & 38 \\
\hline Hypersomnia & 100 & 41 & 33 & 20 & 55 & 50 & 0 & 0 & 73 & 52 \\
\hline Insomnia & 100 & 35 & 33 & 23 & 45 & 50 & 0 & 100 & 59 & 45 \\
\hline Parasomnias & 100 & 71 & 67 & 37 & 75 & 100 & 0 & 0 & 92 & 72 \\
\hline Behavioral insomnia of childhood & 100 & 53 & 44 & 37 & 75 & 100 & 0 & 0 & 92 & 69 \\
\hline Sleep apnea & 100 & 94 & 44 & 63 & 95 & 100 & 100 & 100 & 91 & 83 \\
\hline Sleep related rhythmic movements & 100 & 41 & 22 & 29 & 95 & 50 & 0 & 0 & 64 & 49 \\
\hline Sleep in medical disorders & 67 & 41 & 22 & 23 & 25 & 100 & 100 & 0 & 39 & 33 \\
\hline
\end{tabular}

Note:

- Percentages presented are the percentage of respondents in each country that indicated a topic is covered in their curriculum.

- Zeros indicate that respondents reported no coverage of sleep education in general or for a specific topic.

\section{Barriers to sleep education}

The three most common barriers identified by the respondents, if sleep was not adequately covered in the curriculum, were lack of qualified staff (53\%), insufficient time $(47 \%)$, and a lower priority (46\%). Other barriers included lack of resources (29\%) and lack of relevance $(9 \%)$.

\section{Discussion}

In contrast to sleep-related education in medical schools, there appears to be more coverage of sleep and sleep disorders in pediatric residency programs, albeit limited. Overall, the median amount of time spent on sleep education was 2 hours (mean $=4.4$ hours), with one-quarter of programs responding that their pediatric residency program provides no education regarding sleep. As expected, there were significant country-based differences, with one country providing very limited education (Indonesia), one country only focusing on sleep apnea/respiratory (Thailand), while other countries cover the breadth of sleep problems (Hong Kong, India, and United States-Canada). There was also significant differences in coverage based on topic area, with $83 \%$ of all programs indicating coverage of sleep apnea (and some countries reporting 100\%), compared to just a third of programs covering such topics as delayed sleep phase syndrome and sleep in medical disorders.
Previously, a survey of U.S. medical schools conducted in 1990 reported that medical students received about 2 hours of sleep education, with 13\% reporting no education in the preclinical years [6]. Similarly, a study of medical schools conducted in 2011 [7] found sleep education coverage of approximately 2 hours. In comparison, the mean hours of education in pediatric residency programs reported in 1994 in the US was 4.8 hours (median =0). At that time, $46 \%$ of programs reported no inclusion of sleep education. Interestingly, the mean hours of education in this study was the exact same (although in the US it has actually decreased to 2.7 hours), although the median did increase substantially, as well as the percentage of programs that provide any education ( $77 \%$ vs $54 \%)$.

Interestingly, many programs report providing nondidactic educational opportunities, primarily through journal clubs, speakers, and case consults. Less than half have elective rotations, and only $20 \%$ offer a nonelective rotation. Compared to the previous study of 156 pediatric residency programs in the United States conducted in 1994 [8], this is a significant increase in the availability of non-elective ( $20 \%$ vs $4 \%$ ) and elective rotations ( $40 \%$ vs $25 \%$ ). All other non-didactic opportunities are either similar in prevalence or slightly less common than almost 20 years ago. Note that this study 
assessed education in multiple countries compared to just US programs from 1994.

The primary obstacles to providing sleep education were insufficient time and lack of qualified instructors. However, disappointingly, almost half of the programs indicated that the inclusion of pediatric sleep education was a low priority. Compared to the previous study of medical schools [7], this was a more prevalent barrier cited. Given that many of the residents in these programs will be involved in primary care, it is important to include education on how common pediatric sleep issues are a concern of parents, and that residents need to be educated on this frequent and important issue.

As with former surveys of this type, it is possible that the results provided overestimate the amount of sleep education provided in residency programs, as it is probable that those who responded were more likely to be from programs in which sleep education was provided. Excluding Japan, the response rate was higher than in previous studies, but still these results may not be representative of sleep education as a whole in residency programs. In contrast, the hours of education are probably an underestimate given that sleep concerns are likely to arise in daily patient care, both in primary care settings and in specialty clinics. Thus, sleep-related information that is imparted within these kinds of settings is unlikely to be reported. Furthermore, the exact hours of education reported was likely subject to interpretation by the program directors. That is, some program directors may have only considered didactic lectures in their reporting, whereas others may have included non-didactic teaching. Thus, the large discrepancies between countries, especially of those of similar level of development and educational maturity, may be due to differences in defining educational hours by the program director responding to the survey. Furthermore, future research should specifically survey pediatric residents about their perspective regarding sleep education in their residency programs.

Over the past years, there has been a significant increase in the recognition of sleep disorders in general, and specifically in pediatrics. In 2002, the American Academy of Pediatrics released guidelines that every child should be screened for snoring [11] and the in 2006 the American Academy of Sleep Medicine developed standards of practice guidelines for behavioral treatments of bedtime problems and night wakings [12]. Furthermore, practice parameters have been released giving indications for polysomnography in pediatric patients. However, in contrast, there appears to be a limited increase in sleep education provided in pediatric residency programs. Thus, there needs to be a continued push for inclusion of sleep education in the training of pediatric specialists.

\section{Conclusions}

In contrast to sleep-related education in medical schools, there appears to be more coverage of sleep and sleep disorders in pediatric residency programs, albeit quite limited. These results indicate that there is still a need for more efforts to include sleep-related education in all pediatric residency programs, as well as coverage of the breadth of sleep-related topics. Such education would be consistent with the increased recognition of the importance of sleep and under-diagnosis of sleep disorders in children and adolescents.

\section{Additional file}

Additional file 1: Pediatric Residency Sleep Education Survey.

\section{Competing interests}

The authors declare that they have no competing interests.

\section{Authors' contributions}

All authors substantially contributed to the design of the study and data acquisition. JM performed the statistical analyses and drafted the manuscript. $A B$ and $D G$ revised the manuscript for intellectual content. All authors read and approved the final manuscript.

\section{Acknowledgements}

This study was conducted by the Asia-Pacific Pediatric Sleep Alliance and supported by Johnson \& Johnson Consumer Products Company, Division of Johnson \& Johnson Consumer Companies, Inc.

\section{Author details}

'The Children's Hospital of Philadelphia and Saint Joseph's University, Philadelphia, USA. ${ }^{2}$ Sleep Well Clinics, Christchurch, New Zealand. ${ }^{3}$ Eulji University School of Medicine, Daejeon, South Korea. ${ }^{4}$ National University Hospital, Singapore, Singapore. ${ }^{5}$ University of Medicine and Pharmacy, HCMC, Ho Chi Minh, Vietnam. ${ }^{6}$ Tokyo Bay Urayasu/lchikawa Medical Center, Tokyo, Japan. ${ }^{7}$ Prince of Wales Hospital, The Chinese University of Hong Kong, Ma Liu Shui, Hong Kong. ${ }^{8}$ Faculty of Medicine, Mahidol University, Nakhon Pathom, Thailand. ${ }^{9}$ Medical School University of Indonesia, Jakarta, Indonesia. ${ }^{10}$ Sydney Children's Hospital and University of New South Wales, Sydney, Australia. ${ }^{11}$ National University of Singapore, Singapore, Singapore.

Received: 8 November 2012 Accepted: 19 March 2013

Published: 3 April 2013

\section{References}

1. Meltzer LJ, Johnson C, Crosette J, Ramos M, Mindell JA: Prevalence of diagnosed sleep disorders in pediatric primary care practices. Pediatrics 2010, 125(6):e1410-e1418.

2. IOM: Sleep disorders and sleep deprivation: An unmet public health problem. Washington: The National Academies Press; 2006.

3. Rosen R, Mahowald M, Chesson A, Doghramji K, Goldberg R, Moline M, Millman R, Zammit G, Mark B, Dement W: The Taskforce 2000 survey on medical education in sleep and sleep disorders. Sleep 1998, 21(3):235-238.

4. Strohl KP, Veasey S, Harding S, Skatrud J, Berger HA, Papp KK, Dunagan D, Guilleminault C: Competency-based goals for sleep and chronobiology in undergraduate medical education. Sleep 2003, 26(3):333-336.

5. Orr WC, Stahl ML, Dement WC, Reddington D: Physician education in sleep disorders. J Med Educ 1980, 55(4):367-369.

6. Rosen RC, Rosekind M, Rosevear C, Cole WE, Dement WC: Physician education in sleep and sleep disorders: a national survey of U.S. medical schools. Sleep 1993, 16(3):249-254.

7. Mindell JA, Bartle A, Wahab NA, Ahn Y, Ramamurthy MB, Huong HT, Kohyama J, Ruangdaraganon N, Sekartini R, Teng A, et al: Sleep education in medical school curriculum: a glimpse across countries. Sleep Med 2011, 12(9):928-931. 
8. Mindell JA, Moline ML, Zendell SM, Brown LW, Fry JM: Pediatricians and sleep disorders: training and practice. Pediatrics 1994, 94(2 Pt 1):194-200.

9. Owens JA: The Practice of Pediatric Sleep Medicine: Results of a Community Survey. Pediatrics 2001, 108(3):e51.

10. Faruqui F, Khubchandani J, Price JH, Bolyard D, Reddy R: Sleep disorders in children: a national assessment of primary care pediatrician practices and perceptions. Pediatrics 2011, 128(3):539-546.

11. American Academy of $\mathrm{P}$ : Clinical practice guideline: Diagnosis and management of childhood obstructive sleep apnea syndrome. Pediatrics 2002, 109(4):704-712.

12. Morgenthaler TI, Owens J, Alessi C, Boehlecke B, Brown TM, Coleman J Jr, Friedman L, Kapur VK, Lee-Chiong T, Pancer J, et al: Practice parameters for behavioral treatment of bedtime problems and night wakings in infants and young children. Sleep 2006, 29(10):1277-1281.

Cite this article as: Mindell et al: Sleep education in pediatric residency programs: a cross-cultural look. BMC Research Notes 2013 6:130.

\section{Submit your next manuscript to BioMed Central and take full advantage of:}

- Convenient online submission

- Thorough peer review

- No space constraints or color figure charges

- Immediate publication on acceptance

- Inclusion in PubMed, CAS, Scopus and Google Scholar

- Research which is freely available for redistribution 